\title{
Degenerate PCR Method for Identification of an Antiapoptotic Gene in BHV-1
}

\author{
G. Marfè, ${ }^{1}$ L. De Martino, ${ }^{2}$ G. Filomeni, ${ }^{3}$ C. Di Stefano, ${ }^{1}$ M.G. Giganti, ${ }^{1}$ U. Pagnini, ${ }^{2}$ F. Napolitano, ${ }^{4}$ \\ G. Iovane, ${ }^{2}$ M.R. Ciriolo, ${ }^{3}$ and P. Sinibaldi Salimei ${ }^{1}{ }^{*}$ \\ ${ }^{1}$ Department of Experimental Medicine and Biochemical Sciences, \\ University of Rome "Tor Vergata"—Via Montpellier 1, 00133 Rome, Italy \\ ${ }^{2}$ Department of Pathology and Animal Health, Infectious Diseases, Medicine Veterinary College, \\ University of Naples "Federico II", Via F. Delpino 1-80137, Naples, Italy \\ ${ }^{3}$ Department of Biology, University of Rome Tor Vergata via della Ricerca Scientifica 1, 00133 Rome, Italy \\ ${ }^{4}$ Istituto Sperimentale per la Zootecnia, Via Salaria 31, 00016 Monterotondo Rome, Italy
}

\begin{abstract}
To investigate on the hypothetical presence of an antiapoptotic gene, we utilized the CODEHOP (COnsensus-DEgenerate Hybrid Oligonucleotide Primers) strategy amplifying unknown sequences from a background of genomic (bovine herpesvirus type-1) BHV-1 DNA. An alignment of carboxyl-terminal domains belonging to three proteins encoded by $\gamma 34.5$, MyD116 and GADD34 genes, was carried out to design degenerate PCR primers in highly conserved regions. This allowed the amplification of a $110 \mathrm{bp}$ fragment. This fragment was subjected to automatic sequencing and DNA sequence analysis revealed that its position resided between the nt 14363 and the nt 14438 in bovine herpesvirus type-1 (BHV-1) Cooper strain sharing an identity of 86\% (UL14). Transient transfections showed that UL14 protein is efficient in protecting MDBK and K562 cells from sorbitol induced apoptosis. The protein's anti-apoptotic function may derive from its heat shock protein-like properties. J. Cell. Biochem. 97: 813-823, 2006. (c) 2005 Wiley-Liss, Inc.
\end{abstract}

Key words: BHV-1; apoptosis; PCR degenerate; UL14; CODEHOP

Bovine herpesvirus type-1 (BHV-1), a member of the Alphaherpesvirinae subfamily, causes infectious bovine rhinotracheitis (IBR), and is also associated with a range of various clinical manifestations [Ludwig, 1983]. Like all members of the alpha herpesvirus family, BVH1 , establishes a latent infection in sensory ganglionic neurons of an infected host [Wyler et al., 1989].

BHV-1 is able to cause apoptosis in ConA stimulated bovine peripheral blood mononuclear cells (PBMCs) [Saini et al., 1999], but we have, recently, demonstrated that BHV-1 suppresses sorbitol-induced apoptosis in a manner similar to that of herpes simplex virus type 1

\footnotetext{
*Correspondence to: P. Sinibaldi Salimei, University of Rome "Tor Vergata", Department Experimental Medicine and Biochemical Sciences, 1, Montpellier street, 00133, Rome, Italy. E-mail: paola.sinibaldi@uniroma2.it

Received 25 July 2005; Accepted 27 July 2005

DOI 10.1002/jcb.20636

(c) 2005 Wiley-Liss, Inc.
}

(HSV-1), indicating that BHV-1 has one or more anti-apoptotic genes [De Martino et al., 2003].

During the last several years, apoptosis has become widely accepted as an important nonspecific antiviral host response. Premature death of an infected cell would have obvious deleterious consequences for the production of viral progeny, and, therefore, viruses and their gene products have been considered exquisitely useful tools in the molecular dissection of apoptotic pathways during infection [O'Brien, 1998].

The large DNA-containing viruses have proven to be a rich source of genes with antiapoptotic activity. For example, it is well documented that wild-type herpes simplex virus 1 (HSV-1) blocks apoptosis induced by thermal [Leopardi and Roizman, 1996] or osmotic shock [Koyama and Miwa, 1997]. This has been considered to be an outcome of expression of a viral antiapoptotic gene whose product inhibits one of the steps in the virus-induced signaling leading to apoptosis [Koyama and Miwa, 1997]. Antiapoptotic activities have been identified in adenovirus, Epstein-Barr virus, baculovirus, African 
swine fever virus, cowpox virus, and human cytomegalovirus [Neilan et al., 1993; Zhu et al., 1995].

Cells infected with wild-type HSV-1 do not show the typical factor of apoptosis, in fact, the accumulation of HSV-1 early and late protein correlates with prevention of apoptosis in infected Hep-2 cells [Aubert et al., 2001]. However, the lack of apoptosis in HSV-1infected cells has been considered to be the result of a viral antiapoptosis gene, which inhibits some step in the cellular response toward apoptosis. This idea is supported by finding that the mutant viruses which lack the $\gamma 34.5$ gene induce apoptosis in infected human neuroblastoma cells [Chou and Roizman, 1994] or human foreskin cells [Chou and Roizman, 1992]. Although this mutant virus could grow normally and does not induce apoptosis in Vero cells or in Hep-2cells [Chou and Roizman, 1992], this result has been interpreted as the $\gamma 34.5$ gene product suppressing HSV-1-induced apoptosis in a cell type-specific manner.

The $\gamma 34.5$ gene of HSV-1 is predicted to encode a protein of 263 amino acids consisting of a large amino-terminal domain, a linker or swivel region of three amino acids repeated ten times, and a carboxyl-terminal domain [Chou and Riozman, 1990]. The three-aminoacid repeats (Ala-Thr-Pro, ATP codons) are a constant feature of all strain but the number of repeats varies from strain to strain [Whitley et al., 1993; Chou et al., 1994]. The carboxylterminal domain is a partially homologous to the corresponding domains of protein encoded by MyD116 gene and growth arrest and DNA damage gene 34 (GADD34) [Chou and Roizman, 1992; He et al., 1996]. The MyD116 gene has been cloned from murine myeloid leukaemia cells induced to differentiate by interleukin IL-6 [Lord et al., 1990] and the MyD116 protein is predicted to consist of a large amino-terminal domain, a 38-amino acid sequence repeated 4.5 times, and $\alpha$-carboxyl-terminus containing sequences partially homologous to an 82-amino acid stretch in $\gamma 34.5$ protein [He et al., 1996]. The hamster GADD34 gene induced by growth arrest and DNA damage predicts a similar protein as $\gamma 34.5$ and MyD116 [Zhan et al., 1994]. On the basis of this finding, both for highly conserved carboxyl-terminal domain and their capacity to block apoptotic process, $\gamma 34.5$, MyD116 and GADD34 proteins were chosen in order to design degenerate primers.
Procedures using PCR to amplify novel members of gene families from genomic DNA frequently involve the use of the degenerate primers. Of key importance is the ability to produce ample quantities of specific PCR product while minimizing or eliminating nonspecific side reactions. Here we have used the strategy called Consensus-Degenerate Hybrid Oligonucleotide Primers (CODEHOP) [Rose et al., 1998]. Hybrid primers consist of a relatively short $3^{\prime}$ degenerate core and a $5^{\prime}$ non-degenerate consensus clamp. Reducing the length of the $3^{\prime}$ core to a minimum decreases the total number of individual primers in the degenerate primer pool. Hybridation of the $3^{\prime}$ degenerate core with the target template is stabilized by the $5^{\prime}$ non-degenerate consensus clamp, which allows higher annealing temperatures without increasing the degeneracy of the pool [Rose et al., 1998].

The aim of this study is to utilize this strategy in order to identify a novel gene of BHV-1 with antiapoptotic activity and to examine the antiapoptotic function of UL14 gene product.

\section{MATERIALS AND METHODS}

\section{Virus}

The BHV-1 Cooper strain was kindly provided by Prof. Castrucci (University of Perugia, Italy). Virus stocks were routinely grown on MDBK cells (American Type Culture Collection) and were also used for determination of virus titers. The virus was purified as described by Lyaku et al. [1992], resuspended in Dulbecco's modified Eagle's medium (DMEM) (Eurobio, Les Ulis Cedx B, France) supplemented with $2 \mathrm{mM}$ L-glutamine (Bio-Whittaker, Rockland, ME), and stored in liquid nitrogen until use.

\section{Cells and Culture Conditions}

Madin-Darby bovine kidney (MDBK) and human chronic myelogenous leukemia (K562) cells from American Type Culture Collection in this study were used. MDBK cells were cultured in DMEM supplemented with $2 \mathrm{mM}$ L-glutamine, 5\% pre-screened and heat-inactivated fetal calf serum (FCS) (Eurobio), $100 \mathrm{IU}$ of penicillin, and $100 \mathrm{mg}$ of streptomycin per $\mathrm{ml}$ (both antibiotics from Bio-Whittaker), in a 5\% $\mathrm{CO}_{2}$ incubator.

K562 cells were grown in RPMI 1640 medium supplemented with $10 \%$ heat-inactivated fetal 
bovine serum at $37^{\circ} \mathrm{C}$ in an atmosphere containing $5 \% \mathrm{CO}_{2}$.

\section{Extraction of BHV-1 DNA by Method of Hirt}

A MDBK cell monolayer infected with BHV-1 stock was scraped off the culture after confluent cytopathic effect, and the infected cells were collected by low-speed centrifugation in a microfuge tube. The pellet was resuspended in a solution containing $0.01 \mathrm{M}$ Tris- $\mathrm{HCl}(\mathrm{pH} 8.0)$, $0.01 \mathrm{M}$ EDTA and lysed by adding $0.6 \%$ SDS. Five $\mathrm{M} \mathrm{NaCl}$ was added to a final concentration of $1 \mathrm{M}$ and the lysates was maintained overnight at $4^{\circ} \mathrm{C}$. After centrifugation at $4^{\circ} \mathrm{C}$ for $30 \mathrm{~min}$ at $1,5000 \mathrm{rpm}$, the cellular pellet was removed from the microfuge tube using a toothpick. The supernatant was extracted once with phenol, twice with phenol/chloroform (1:1 v/v) and once with chloroform. Two volumes ethanol was added to the final aqueous phase and the mixture was stored at -70 to precipitate the DNA [Umene, 1985].

\section{Extraction of Genomic DNA}

Cells were washed twice with phosphatebuffered saline (PBS) and lysed by addition of an extraction buffer containing $5 \mathrm{mM}$ ethylene diaminetetra-acetic acid (EDTA), $10 \mathrm{mM}$ Tris$\mathrm{HCl}$ (pH 8.0), $50 \mathrm{mM} \mathrm{NaCl} \mathrm{1 \%} \mathrm{sodium} \mathrm{dodecyl-}$ sulfate (SDS), and $400 \mu \mathrm{g} / \mathrm{ml}$ Proteinase $\mathrm{K}$ (20 mg/ml, Sigma Aldrich Co. St. Louis, MO), incubated at $50^{\circ} \mathrm{C}$ overnight. Then, DNA samples were digested with $10 \mathrm{mg} / \mathrm{ml}$ Rnase A for $1 \mathrm{~h}$ at $37^{\circ} \mathrm{C}$ and purified through consecutive $\mathrm{TE}$ (10 mM Tris- $\mathrm{HCl}$ and $0.1 \mathrm{mM}$ EDTA, $\mathrm{pH}$ 8.0)saturated phenol, phenol-chloroform $(1: 1 \mathrm{v} / \mathrm{v})$ and chloroform extractions. Finally, DNA samples were precipitated with $0.3 \mathrm{M}$ sodium acetate at $\mathrm{pH} 5.2$ and 2.5 volumes of cold ethanol, centrifuged for $30 \mathrm{~min}$ at maximum speed at $4{ }^{\circ} \mathrm{C}$, washed in $70 \%$ cold ethanol and resuspended in sterile water. Concentrations of the extracted DNAs were evaluated by spectro- photometric analysis at $260 \mathrm{~nm}$ and were stored at $-20^{\circ} \mathrm{C}$.

\section{RNA Isolation and cDNA Preparation}

The total RNA, extracted by guanidium thiocyanate method, was isolated from MDBK cells. The total RNA pellet was dissolved in $100 \mu \mathrm{l}$ of nuclease-free water. RNA was reverse transcribed by using a random hexanucleotide primer with Superscript II Reverse Transcriptase from Invitrogen according to the manufacturer's instructions. First-strand cDNA will be prepared by incubation of $1 \mu \mathrm{g}$ of total RNA with Superscript II reverse transcriptase at $42^{\circ} \mathrm{C}$ for $50 \mathrm{~min}$ with the final stage at $70^{\circ} \mathrm{C}$ for $15 \mathrm{~min}$.

\section{Degenerate PCR}

Eight primers were designed using COnsensus-DEgenerate Hybrid Oligonucleotide Primers (CODEHOP) strategy. Temperature cycles for the set of primers were as followed $1 \mathrm{~min}$ at $94^{\circ} \mathrm{C}, 2 \mathrm{~min}$ at $59^{\circ} \mathrm{C}$, and $2 \mathrm{~min}$ at $72^{\circ} \mathrm{C}$. These cycles were carried out 40 times. The primers used are listed in Table I. Twenty microliters of the PCR products were electrophoresed in $1.5 \%$ agarose gel.

\section{Rapid Gel Extraction DNA}

The area of gel containing the DNA fragment was cut. For the DNA extraction, Concert gel extraction System Kit (Life Tecnologies, Gibco) was used.

\section{Nucleotide Sequencing}

Cycle sequencing was performed using the BigDye version 2.0 terminator cycle-sequencing kit according to manufacturer's instructions (Applied Biosystems). Primers were added to a final concentration of $300 \mathrm{nmol} / \mathrm{L}$ in a $20-\mu \mathrm{l}$ reaction volume. Cycle-sequencing conditions were $95^{\circ} \mathrm{C}$ for $30 \mathrm{~s}$, followed by 35 cycles of $95^{\circ} \mathrm{C} \times 15 \mathrm{~s}, 50^{\circ} \mathrm{C} \times 15 \mathrm{~s}$, and $60^{\circ} \mathrm{C} \times 4 \mathrm{~min}$.

TABLE I. Oligonucleotide primers used in PCR

(A) Forward primers ICP34,5 (5'-3')

Sequence

(B) Reverse primers ICP34,5 $\left(3^{\prime}-5^{\prime}\right)$

\section{ACCGTGCACCACCTGGCGGTGTGGGC}

$\begin{array}{ll}\mathrm{C} & \mathrm{C} \\ \mathrm{A} & \mathrm{T} \\ \mathrm{T} & \mathrm{A}\end{array}$

CGGGTCCGGCTCCTCTTCTAGCCGGGG

$\begin{array}{lll}\text { CC } & \text { T } & \text { C } \\ \text { TG } & \text { C } & \text { CT }\end{array}$ 
Products were analyzed by using an ABI Prism 3700 (Applied Biosystems).

\section{Plasmid Construction and Establishment of Inducible UL14-Expressing Cell Lines}

The UL14 region of BHV-1 was amplified by polymerase chain reaction (PCR) using the primer pairs 5'-ATGGCGACGGCGGC and 5'TGCTGTGGGGCGGC. The amplified fragment was insert in sense orientation into pBK-CMV vector to generate $\mathrm{pBK}-\mathrm{CMV}-\mathrm{UL} 14$.

The pBK-CMV-UL14 plasmid was transfected into MDBK and K562 cells using Lipofectamine according to the instruction of the manufacturer (Boehringer). Briefly, the pBKCMV-UL14 plasmid was diluted to a concentration of $0.1 \mu \mathrm{g} / \mu \mathrm{l}$ in $20 \mathrm{mM}$ HEPES buffer ( $\mathrm{pH}$ 7.5). The DNA solution was added to diluted DOTAP liposomal transfection reagent (Boehringer) containing $240 \mu \mathrm{l}$ of DOTAP and $720 \mu \mathrm{l}$ of $20 \mathrm{mM}$ HEPES buffer ( $\mathrm{pH}$ 7.5). The transfection mixture was incubated at room temperature for $15 \mathrm{~min}$, mixed with $6.5 \mathrm{ml}$ of DMEM containing $5 \%$ fetal calf serum, penicillin and streptomycin for MDBK cells and RPMI 1640 containing 10\% fetal calf serum, penicillin, and streptomycin for K562 cells. At $24 \mathrm{~h}$ after transfection, the transfection mixture was removed and the cells were incubated with $5 \mathrm{ml}$ of fresh medium containing $1 \mathrm{M}$ sorbitol for $1 \mathrm{~h}$. After the treatment the cells were washed with PBS buffer and in order to verify the expression of UL4 construct PCR was performed. Furthermore, to examine the effect of UL14 expression on sorbitol-induced apoptosis the DNA fragmentation in transfected cells was evaluated.

\section{DNA Fragmentation Assay}

Briefly, MDBK and K562 cells were washed twice with PBS and lysed by addition of a hypotonic solution $(50 \mathrm{mM}$ Tris- $\mathrm{HCl} \mathrm{pH} 7.5$, $20 \mathrm{mM}$ EDTA, 1\% NP-40). After centrifugation for $5 \mathrm{~min}$ at $160 \mathrm{~g}$, supernatants were treated with $1 \%$ SDS and RNase A (final concentration $5 \mu \mathrm{g} / \mu \mathrm{l})$ for $2 \mathrm{~h}$ at $56^{\circ} \mathrm{C}$, followed by digestion with proteinase $\mathrm{K}$ (final concentration $2.5 \mu \mathrm{g} / \mu \mathrm{l}$ ) at $45^{\circ} \mathrm{C}$ for at least $6 \mathrm{~h}$. Before hydrolysis a further cleaning of DNA was performed by phenol-chloroform extraction. Pellets were dried for $30 \mathrm{~min}$ and resuspended in $200 \mu \mathrm{l}$ Tris-EDTA pH 8.0 [Herrmann et al., 1994] Aliquots of $20 \mu \mathrm{l}$ containing $10 \mu \mathrm{g}$ DNA were analyzed by electrophoresis on $1.8 \%$ ethidium bromide-containing agarose gels and visualized and quantitated under UV transillumination of apparatus BioRad Gel Doc 1000 (BioRad) with the program Quantity One. Sizes of DNA fragments in the samples were compared with standard size fragments in a $1 \mathrm{~kb}$ DNA ladder (Invitrogen).

\section{Western Blot Analyses}

K562 cell pellet was resuspended in lysis buffer containing $10 \mathrm{mM}$ Tris- $\mathrm{HCl}, \mathrm{pH} 7.4,5 \mathrm{mM}$ EDTA, $150 \mathrm{mM} \mathrm{NaCl}, 0.5 \%$ IGEPAL CA-630, and protease inhibitors. After $30 \mathrm{~min}$ incubation on ice, cells centrifuged at $14,000 \mathrm{~g}$ for $15 \mathrm{~min}$ at $4^{\circ} \mathrm{C}$, and supernatants were stored at $-80^{\circ} \mathrm{C}$. Twenty micrograms of proteins were loaded on $10 \%$ polyacrylamide gel and transferred onto a nitrocellulose membrane (Bio-Rad). Monoclonal anti-caspase-9 (1:1,000) (Upstate) was used as primary antibody. The specific protein complex, formed upon anti-mouse secondary antibody treatment $(1: 5,000)$, was identified using FLUORCHEM SuperSignal substrate chemiluminescence reagent.

\section{RESULTS}

\section{Primer Design}

The hybrid primer strategy was tested on problems in which the target sequence for amplification was unknown but could be predicted from multiply aligned protein sequences. We utilized the automated CODEHOP prediction program to design optimal primers from BlockMarker-generated alignments of different proteins in order to identify a new antiapoptotic member in BHV-1.

We have predicted that the BHV-1 genome might contain an antiapoptotic gene and to identify and characterize it, the amino acid sequences of three different proteins were multiply aligned.

It is known that the sequence comparison of three proteins encoded by $\gamma 34.5$, MyD116 and GADD34 genes, detected a highly conserved carboxyl-terminal domain and this similarity was sufficient to allow us the design of a set of degenerate primers for our study. The primer sites were located in two short conserved regions of the three considered proteins that are believed to be involved in apoptotic process. The use of degenerate PCR facilitates the isolation of genes which could also be phylogenetically different and share only short 


\section{BLOCKS from MOTIF}

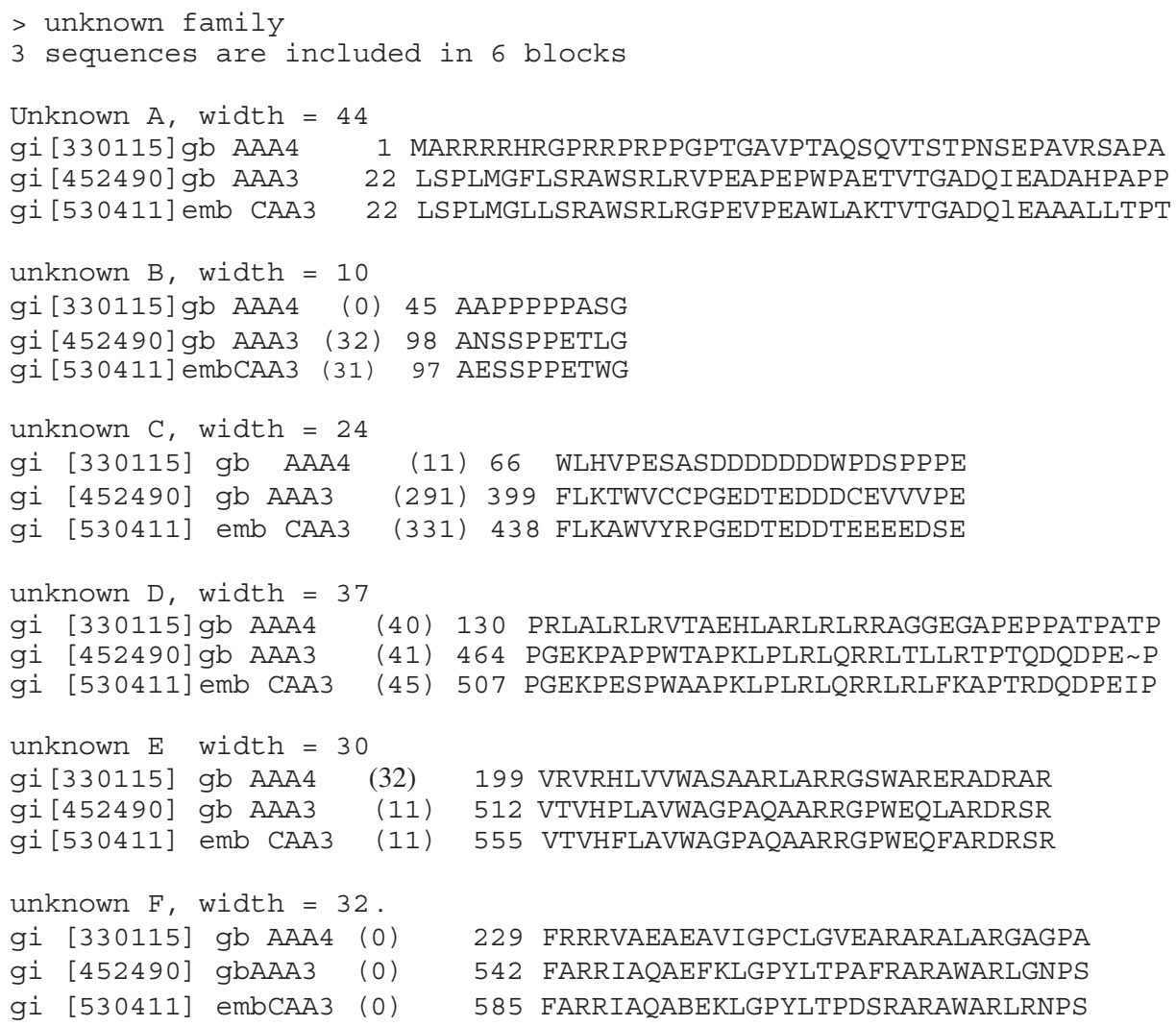

Fig. 1. The design strategy for the most conserved sequence blocks.

\section{Block unknownE}

$\begin{array}{lllllllllllll}\text { V } & \text { T } & \text { V } & \text { H } & \text { H } & \text { L } & \text { A } & \text { V } & \text { W } & \text { A }\end{array}$

oligo:5 '-GTGACCGTGCACCACCTngyngtntggg-3 ' degen=128 temp=59.0

$\begin{array}{lllllllllllllll}\text { T } & \text { V } & \text { H } & \text { H } & \text { L } & \text { A } & \text { V } & \text { W } & \text { A }\end{array}$

oligo:5 '-ACCGTGCACCACCTGgyngtntgggc-3 ' degen $=32$ temp $=60,1$

Complement of Block unknownF

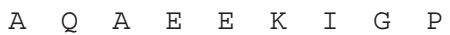

cgnstycgnetCCTCTTCTAGCCGGGG oligo:5'-GGGGCCGATCTTCTCCengcytsngc-3' degen $=64$ temp $=60,1$

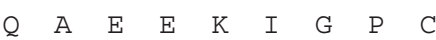

gnstycgnctycTCTTCTAGCCGGGGACG oligo:5' -GCAGGGGCCGATCTTCTCytengcytsng-3' degen $=128$ temp $=62,1$

$\begin{array}{lllllllll}G & P & C & L & T & P & E & F & R\end{array}$

cenggnayrraCTGGGGGCTGAGGGC oligo: 5' -CGGAGTCGGGGGTCarryanggnec- 3' DEGEN $=128$ TEMP $=64,3$

Fig. 2. Primers were designed from these two regions. 


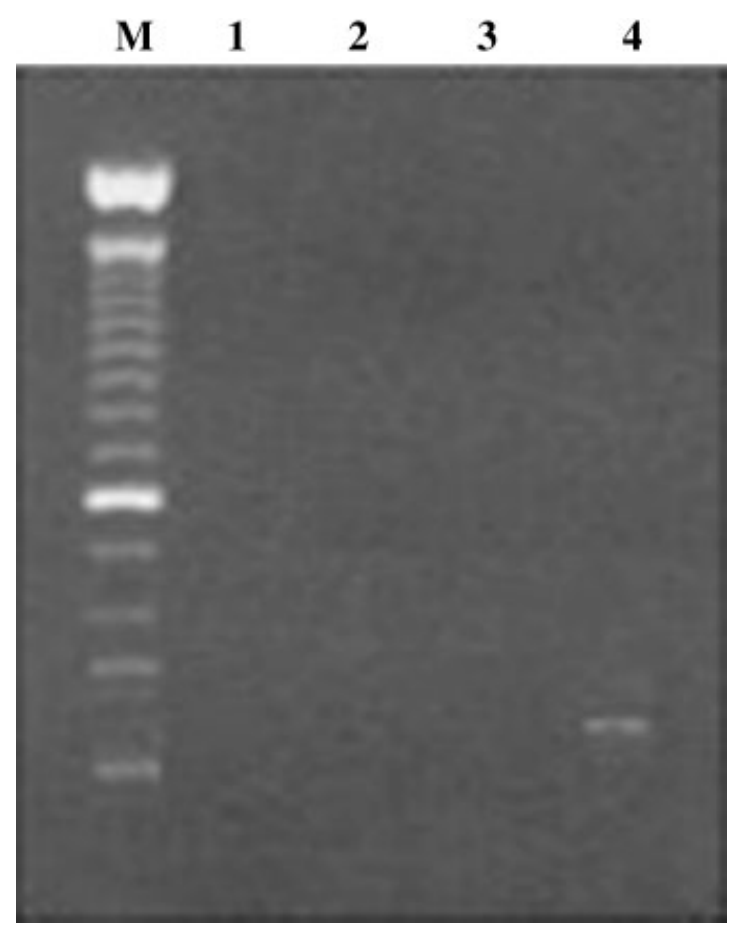

Fig. 3. Degenerate oligo-primed PCR analysis of genomic DNA BHV-1. Lane 1: Molecular weight marker (100 bp DNA ladder). Lane 2: control without template. Lane 3: genomic DNA MDBK cells as control. Lane 4: cDNA MDBK cells as control. Lane 5: fragment of genomic DNA BHV-1.

regions of amino acid sequence; in fact, the nucleotide sequence of $\gamma 34.5$ gene has not similarity with MyD116 and GADD34 which instead present a moderately nucleotide sequence homology.

Visual examination of the alignment revealed five blocks that contained invariant regions suitable for primer prediction: two blocks were chosen for primer design after evaluation of codon possibility within the blocks and distance between blocks. Primers were designed from these three regions using all codon possibilities for the $3^{\prime}$ degenerate core and the most frequent nucleotide in each position for the $5^{\prime}$ consensus clamp.

The CODEHOP strategy provides guidelines to design efficient primers by limiting the degeneracy to just the $3^{\prime}$ core region of length $11-$ $12 \mathrm{bp}$ across four codons of highly conserved amino acids and is non-degenerate at the $5^{\prime}$ consensus clamp region of $26-27 \mathrm{bp}$.

The design strategy for the most conserved sequence block is shown in Figures 1 and 2 .

\section{Detection of Novel Gene Using Hybrid Primers}

The degenerate PCR was carried out using the viral DNA of BHV-1 as template for PCR and the DNA and cDNA of MDBK cells as controls. A PCR product of $110 \mathrm{bp}$, visible by ethidium bromide staining after agarose gel electrophoresis, is shown in Figure 3.

In Figure 4 the DNA sequence analysis of this product is reported.

The alignment, performed with Blast Search program, showed that the product sequence was well overlapped to the DNA sequence of BHV-1 Cooper strain, exactly in the position between the nt 14363 and the nt 14438 (Fig. 5). Such overlapping shared an identity of $86 \%$. Interestingly, the presence of this sequence in the UL14 region of BHV-1 Cooper strain corresponds to a putative protein (Fig. 6).

\section{Antiapoptotic Activity of UL14}

In order to investigate the role of UL14 in BHV-1-induced antiapoptotic responses, MDBK and K562 cells were transfected with pBKCMV-UL14 plasmid (Fig. 7A,B). The effect of UL14 on apoptosis was investigated in cells treated with $1 \mathrm{M}$ sorbitol. UL14 expression rendered both cell lines resistant to apoptosis induced by sorbitol treatment as measured by the suppression of the DNA fragmentation (Fig. 8A,B). This inhibitory effect was not observed in UL14-negative MDBK cells (Fig. 8A) confirming that UL14 protein is required for the antiapoptotic activity (Fig. 9).

Induction of apoptosis results in the activation of caspases. We therefore tested whether UL14 affects the activation of caspase-9 in sorbitol-treated K562 cells.

A slight reduction of the intensity of procaspase-9 immunoreactive band together to an evident activation of caspase-9 in K562 Ul14negative cells was observed (Fig. 9). In contrast,

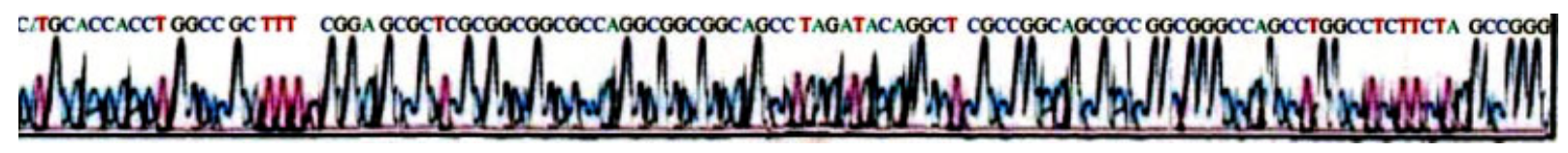

Fig. 4. Nucleotide sequence of fragment. [Color figure can be viewed in the online issue, which is available at www.interscience.wiley.com.] 


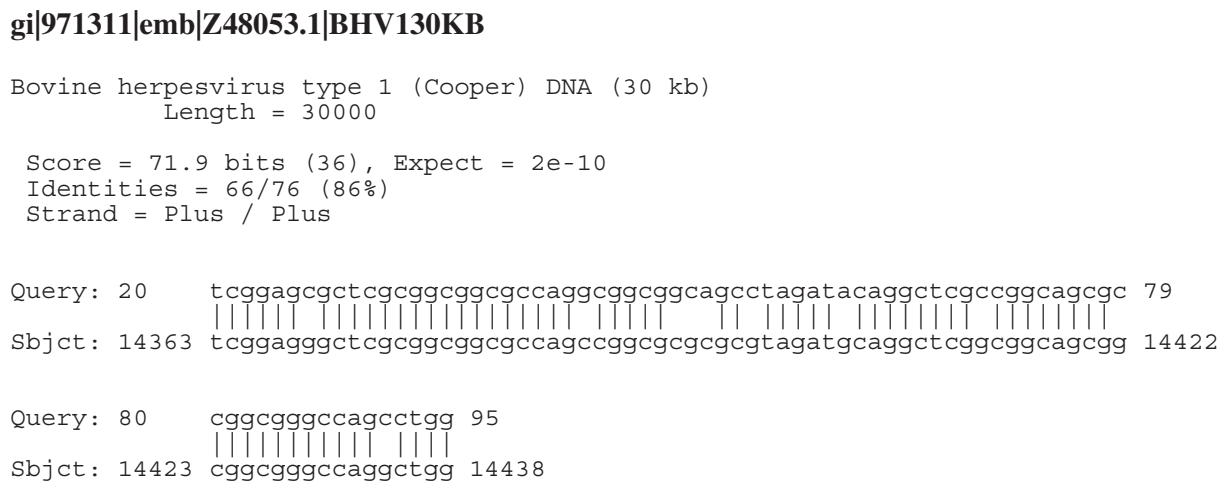

Fig. 5. The alignment was done using Blast Search program.

we observed in K562 UL14-positive cells the lack of caspase- 9 activation as demonstrated by Western blot analysis (Fig. 9). Thus, expression of UL14 appears to be important for the inhibition of caspase activation.

\section{Homology Between the Substrate-Binding Domain of HSP70 and an N-Terminal Region of BHV UL14}

Recently, it was demonstrated that UL14 protein of HSV-2 has HSP-like properties [Yamauchi et al., 2002]. In the course of this research, we searched for homologous amino acid sequence among BHV-1 UL14, HSV-1 UL14, HSV-2 UL14, and human heat shock protein (HPS70). Interestingly, BHV-1 UL14 and HSV UL14 proteins possessed an amino acid sequence that was homologous to a part of the peptide-binding domain conserved in human HSP70 family (Fig. 10A). The homologous domain of BHV-1 UL14 protein is a stretch of 36 amino acids starting from Ala51. In particular, 7 of 14 amino acids (Fig. 10B) in a stretch beginning at the Gly70 of BHV-1 UL14 protein shared homologies with the $\alpha$-helical domain of Hsp70 located at the C-terminal end of the substrate recognition domain. These sequences were conserved in HSV-1, HSV2, and BHV-1 among alfa-herpesviruses and they could be important for the HPS-like properties of UL14 protein.

\section{DISCUSSION}

The use of degenerate oligo-primed PCR is a powerful method to clone new or uncharacterized genes that are related to known gene families [Henikoff et al., 1995] and the two most

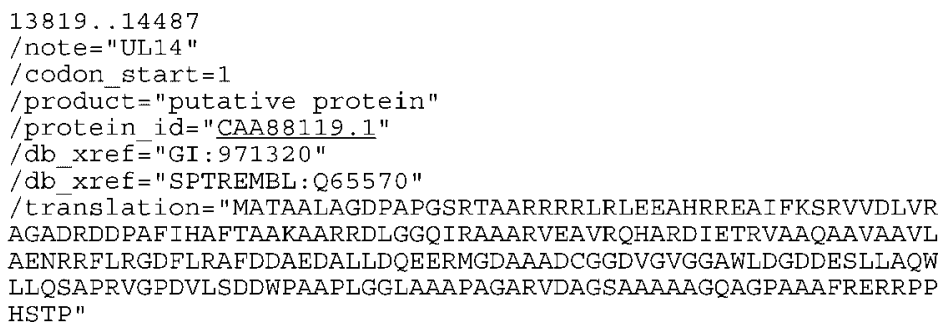

Fig. 6. The sequence of our fragment in the UL14 region of BHV-1 Cooper strain. 
A

MBDK cells

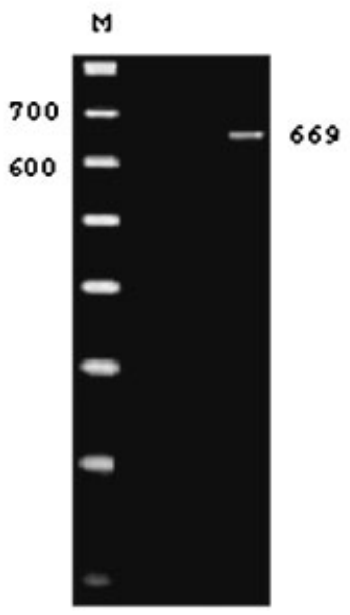

B

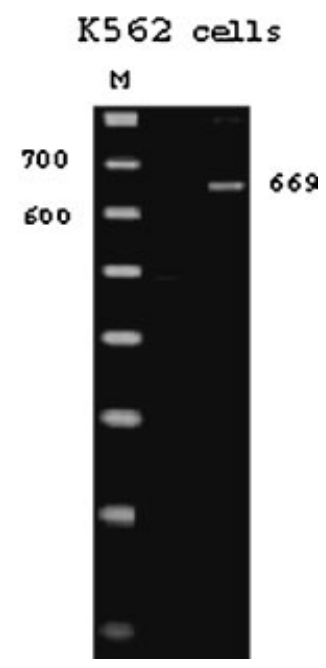

Fig. 7. MDBK (A) and K562 (B) cells were transfected with pBKCMV-UL14. At $24 \mathrm{~h}$ after transfection, total cell lysates were prepared and semiquantitative RT-PCR was performed.

critical factors in degenerate oligo-primed PCR are the design of the primers as well as the PCR conditions.

Moreover, the CODEHOP program utilizes all of the information available in the input alignment and takes into account the codon

A

\section{MDBK cells}

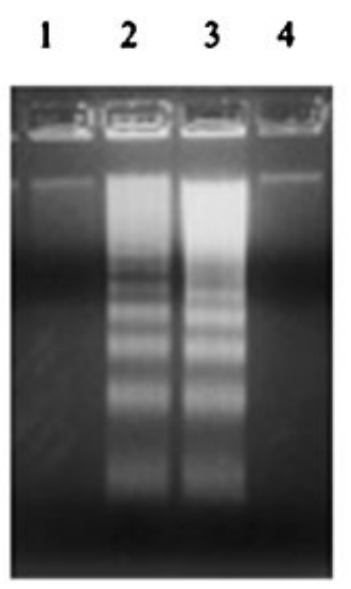

\section{B}

\section{K562 cells}

123

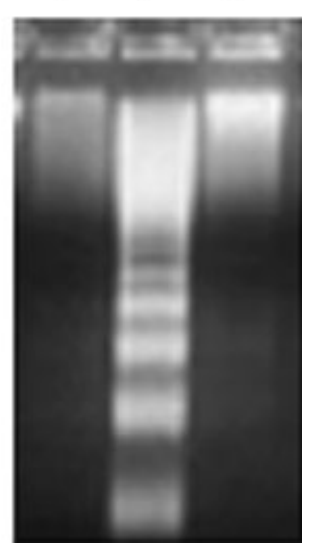

Fig. 8. DNA fragmentation in MDBK (A) and K562 cells (B) after sorbitol treatment. DNA fragmentation in MDBK and K562 cells, transfected with pBK-CMV-UL14 and treated with $1 \mathrm{M}$ sorbitol for $1 \mathrm{~h}$, was suppressed. A (1) MDBK cells (2) MDBK cells and $1 \mathrm{M}$ sorbitol (3) MDBK cells pBK-CMV and $1 \mathrm{M}$ sorbitol (4) MDBK cells pBK-CMV-UL14 and 1M sorbitol B (1) K562 cells (2) K562 cells and $1 \mathrm{M}$ sorbitol (3) MDBK cells pBK-CMV-UL14 and $1 \mathrm{M}$ sorbitol.

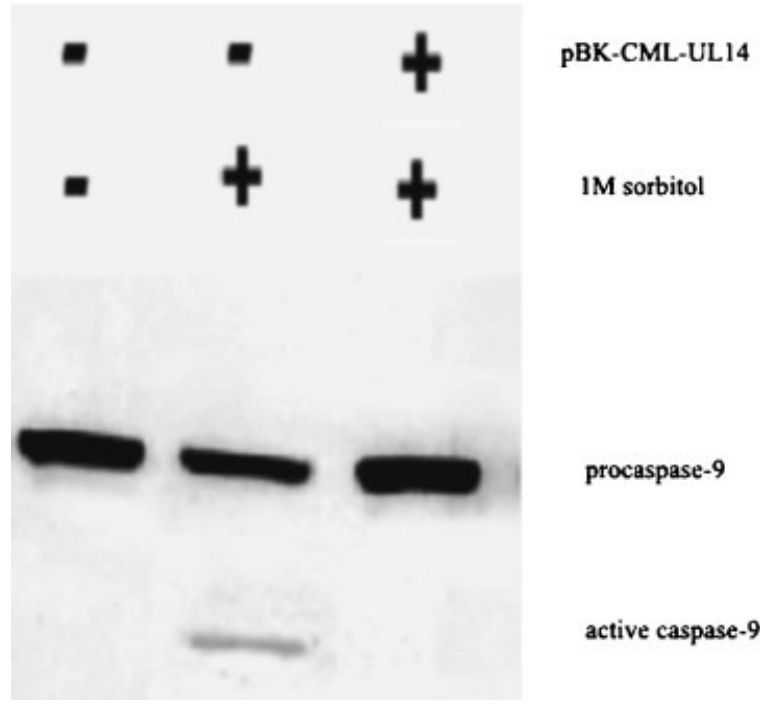

Fig. 9. K562 were collected from cultures untreated and transfected with pBK-CMV-UL14 and after treated with $1 \mathrm{M}$ sorbitol for $1 \mathrm{~h}$. Proteins were subjected to Western blotting and membranes were incubated with anti-caspase-9 antibody.

usage of the target genome to aid in primer design.

In the present study, we have used the sequence comparison of three proteins (that are believed to be involved in apoptosis) for the hybrid primer design strategy, by CODEHOP program, in order to identify a BHV-1 antiapoptotic gene. In particular, we have used the carboxyl-termini of MyD116 and GADD34 proteins, which play a role in blocking apoptosis in terminally differentiated cells and $\gamma 34.5$ HSV-1 protein, that it is able to preclude the premature shutoff of proteins synthesis [Chou and Roizman, 1992]. Based on this similarity, it is conceivable that our product may be involved in antiapoptosis as well.

This strategy allows us to obtain a PCR product of $110 \mathrm{bp}$ whose sequence has well overlapped to the DNA sequence of BHV-1 Cooper strain, exactly in the position between the nt 14363 and the nt 14438 (UL14).

We have further evaluated whether UL14 alter apoptotic response using a transfectant with inducible UL14 expression in two different cell lines. We have demonstrated that expression of UL14 was sufficient for blocking DNA fragmentation induced by sorbitol.

Sorbitol treatment activates caspase- 9 and such activation has been shown in most apoptosis models in two main pathways: a receptoractivated caspase- 8 and -3 , or a cytochrome-c release-dependent caspase- 9 and -3 pathway. In 
A

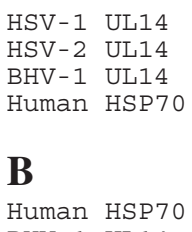

Fig. 10. CLUSTAL W (1.82) multiple sequence alignment.

both pathways, caspase- 3 activation is the final event of caspase cascade [Wagenknecht et al., 2000]. We show here that sorbitol activates caspase-9, and furthermore we have also observed that expression of UL14 appears to be important for the inhibition of caspase-9.

It has been demonstrated that UL14 gene product of HSV-1 has heat shock protein-like functions [Yamauchi et al., 2002].

Recent data have suggested that HSV-2 and HSV-1 UL14 protein shared some characteristics of HSPs or molecular chaperones, such as nuclear translocation upon heat shock, ATP deprivation and osmotic shock [Yamauchi et al., 2002].

Therefore, we can hypothesize that the BHV1 putative protein encoded by UL14 gene could have heat shock protein (HSP)-like functions.

HSPs, particularly those of the HSP70 family, are trascriptionally induced by and associate with viral proteins. It is known that HSP70 is induced during infection by adenovirus, HSV and vaccinia virus [Phillips et al., 1991; Sedger and Ruby, 1994] suggesting that HSP function in viral replication may serve as a common mechanism for these viruses [Cripe et al., 1995; Glotzer et al., 2000].

HSPs are a family of highly conserved proteins, which are induced in both prokaryote and eukaryote in response to an array of physiological and environmental stimuli [Mosser et al., 1993; Lindquist and Craig, 1988]. Induction of HSPs in response to stress serves to protect against the initial insult, augment recovery, and produces a state of resistance to subsequent stress in the cell. This protective role of HSPs can be attributed to several functional properties of protein aggregation and promotion of protein disaggregating by catalysing the refolding of damaged or denaturated proteins [Gething and Sambrook, 1992; Mailhos et al., 1993; Freeman et al., 1995]. In particular, HSP70 protects cells from a number of apoptotic stimuli [Jaattela et al., 1992; Parsell and Lindquist, 1993; Simon et al., 1995].

Several studies suggest that HSP70 is a general apoptosis inhibitor [Samali and Cotter, 1996; Li et al., 2000] similar to such proteins as Bcl-2 [Deveraux and Reed, 1999], IAPs [Srinivasula et al., 1998], and CrmA [Ekert et al., 1999].

We have found a homology between BHV1 UL 14 putative protein and HSP70 family protein and the domain with the greatest homology is located in the $\mathrm{N}$-terminal part (residues) BHV1 UL 14 putative protein and C-terminal part (residues) of the $18 \mathrm{kDa}$ peptide-binding domain of human Hsp70. Such domain (residues) contains two four-stranded antiparallel B-sheets and a single a-helix [Kiang and Tsokos, 1998]. The homology is located in the centre of the ahelix. The a-helix of Hsp70 is an eight amino acid stretch [(514) E-I-E-R-M-V-Q-E (521)] and the homology with UL14 is [(76) A-R-V-E-A-VR-Q (84)]. Thus four of eight residues are homologous; the Lys of Hsp70 and the Gly of UL14 may be of particular importance for chaperone function of both proteins.

The presence of the HSP-like gene in BHV-1 convalidates our precedent data about the expression of the procaspase- 3 in the experimental model on the ability of BHV-1 to suppress sorbitol-induced apoptosis [De Martino et al., 2003].

Taken together, we surmise that the HSP-like BHV-1 protein directly binds to and inhibit the activity of key molecules acting at the execution phase of apoptosis in order to prevent cell death.

\section{REFERENCES}

Aubert M, Rice SA, Blaho JA. 2001. Accumulation of herpes simplex virus type 1 early and leaky-late proteins correlates with apoptosis prevention in infected human HEp-2 cells. J Virol 75:1013-1030.

Chou J, Riozman B. 1990. The herpes simplex virus 1 gene for ICP34.5, which maps in inverted repeats, is conserved 
in several limited-passage isolates but not in strain 17syn+. J Virol 64:1014-1020

Chou J, Roizman B. 1992. The $\gamma 34.5$ gene of herpes simplex virus 1 precludes neuroblastoma cells from triggering total shut off of protein synthesis characteristics of programmed cell death in neuronal cells. Proc Natl Aca Sci USA 89:3266-3270.

Chou J, Roizman B. 1994. The herpes simplex virus $1 \gamma_{1} 34.5$ gene function which blocks the response to infection maps to the homologous domain of the gene expressed during growth and DNA damage. Proc Natl Acad Sci USA 91:5247-5251.

Chou J, Poon PW, Johnson J, Roizman B. 1994. Differential response of human cells to deletions and stop codons in the $\gamma 34.5$ gene f herpes simplex virus 1 . J Virol 68:83048311.

Cripe TP, Delos SE, Estes PA, Garcea RL. 1995. In vivo and in vitro association of hsc70 with polyomavirus capsid proteins. J Virol 69:7807-7813.

De Martino L, Marfé G, Di Stefano C, Pagnini U, Florio S, Crispino L, Iovane G, Macaluso M, Giordano A. 2003. Interference of bovine herpesvirus 1 (BHV-1) in sorbitolinduced apoptosis. J Cell Biochem 89:373-380.

Deveraux QL, Reed JC. 1999. IAP family proteins suppressor of apoptosis. Genes Dev 13:239-252.

Ekert PG, Silke J, Vaux DL. 1999. Inhibition of apoptosis and clonogenic survival of cells expressing crmA variants: Optimal caspase substrates are not necessarily optimal inhibitors. EMBO J 18:330-338.

Freeman BC, Myers MP, Schumacher R, Morimoto RI. 1995. Identification of a regulatory motif in Hsp70 that affects ATPase activity, substrate binding and interaction with HDJ-1. EMBO J 14:2281-2292.

Gething MJ, Sambrook J. 1992. Protein folding in the cell. Nature 355:33-45.

Glotzer JB, Saltik M, Chiocca S, Michou AI, Moseley P, Cotten M. 2000. Activation of heat-shock response by an adenovirus is essential for virus replication. Nature 407:207-211.

He B, Chou J, Liebermann DA, Hoffman B, Roizman B. 1996. The carboxyl terminus of the murine MyD116 gene substitutes for the corresponding domain of the $\mu_{1} 34.5$ gene of herpes simplex virus to preclude the premature shutoff of total protein synthesis in infected human cells. J Virol 70:84-90.

Henikoff S, Henikoff JG, Alford WJ, Pietrokovski S. 1995. Automated construction and graphical presentation of protein blocks from unaligned sequences. Gene 163: $17-26$.

Herrmann M, Lorenz HM, Voll R, Grunke M, Woith W, Kalden JR. 1994. A rapid and simple method for the isolation of apoptotic DNA fragments. Nucleic Acids Res 22:5506-5507.

Jaattela M, Wissing D, Bauer PA, Li GC. 1992. Major heat shock protein hsp70 protects tumor cells from tumor necrosis factor cytotoxicity. EMBO J 11:3507-3512.

Kiang JG, Tsokos GC. 1998. Heat shock protein $70 \mathrm{kDa}$ : Molecular biology, biochemistry, and physiology. Pharmacol Ther 80(2):183-201.

Koyama AH, Miwa Y. 1997. Suppression of apoptotic DNA fragmentation in herpes simplex virus type 1-infectedm cellr. J Virol 71:2567-2571.

Leopardi R, Roizman B. 1996. The herpes simplex virus major regulatory protein ICP4 blocks apoptosis induced by the virus or by hyperthermia. Proc Natl Acad Sci USA 93:9583-9587.

Li CY, Lee JS, Ko YG, Kim J, Seo JS. 2000. Heat shock protein 70 inhibits apoptosis downstream of cytochrome c release and upstream of caspase-3 activation. J Biol Chem 275:25665-25671.

Lindquist S, Craig EA. 1988. The heat-shock proteins. Annu Rev Genet 22:631-677.

Lord KA, Hoffman-Liebermann B, Liebermann DA. 1990 Sequence of MyD116 cDNA: A novel myeloid differentiation primary response gene induced by IL-6. Nucleic Acid Res 18:2823.

Ludwig H. 1983. Bovine herpesviruses. In: Roinzam B, editor. The herpesviruses. Vol. II. New York: Plenum Press. pp 135-214.

Lyaku JRS, Nettleton PF, Marsden HS. 1992. A comparison of serological relationships among ruminant alphaherpesviruses by ELISA. Arch Virol 124:333-341.

Mailhos C, Howard MK, Latchman DS. 1993. Heat shock protects neuronal cells from programmed cell death by apoptosis. Neuroscience 55:621-627.

Mosser DD, Duchaine J, Bourget L, Martin LH. 1993. Changes in heat shock protein synthesis and heat sensitivity during mouse thymocyte development. Dev Genet 14:148-158.

Neilan JG, Lu Z, Alfonso CL, Kutish GF, Sussman MD, Rock DL. 1993. An African swine fever virus gene with similarity to the protooncogene bcl-2 and the EpsteinBarr virus gene BHRF-1. J Virol 67:4391-4394.

O’Brien V. 1998. Viruses and apoptosis. J Gen Virol 79: 1833-1845.

Parsell DA, Lindquist S. 1993. The function of heat-shock proteins in stress tolerance: Degradation and reactivation of damaged proteins. Annu Rev Genet 27:437496

Phillips B, Abravaya K, Morimoto RI. 1991. Analysis of the specificity and mechanism of transcriptional activation of the human hsp70 gene during infection by DNA viruses. J Virol 65:5680-5692.

Rose TM, Schultz ER, Henikoff JG, Pietrokovski S, McCallum CM, Henikoff S. 1998. Consensus-degenerate hybrid oligonucleotide primers for amplification of distantly related sequences. Nucleic Acids Res 26: $1628-1635$.

Saini M, Sharma B, Singh LN, Gupta PK. 1999. Apoptosis in bovine herpesvirus-1 infected bovine peripheral blood mononuclear cells. Indian J Exp Biol 37:976-997.

Samali A, Cotter TG. 1996. Heat shock proteins increase resistance to apoptosis. Exp Cell Res 223:163-170.

Sedger L, Ruby J. 1994. Heat shock response to vaccinia virus infection. J Virol 68:4685-4689.

Simon MM, Reikerstorfer A, Schwarz A, Krone C, Luger TA, Jaattela M, Schwarz T. 1995. Heat shock protein 70 overexpression affects the response to ultraviolet light in murine fibroblasts. Evidence for increased cell viability and suppression of cytokine release. J Clin Invest 95: 926-933.

Srinivasula SM, Ahmad M, Fernandes-Alnemri T, Alnemri ES. 1998. Autoactivation of procaspase-9 by Apaf-1mediated oligomerization. Mol Cell 1:949-957.

Umene K. 1985. Intermolecular recombination of the herpes simplex virus type 1 genome analysed using two strains differing in restriction enzyme cleavage sites. J Gen Virol 66:2659-2670. 
Wagenknecht B, Hermisson M, Groscurth P, Liston P, Krammer PH, Weller M. 2000. Proteasome inhibitorinduced apoptosis of glioma cells involves the processing of multiple caspases and cytochrome c release. $\mathrm{J}$ of Nuerochem 75:2288-2297.

Whitley RJ, Kern ER, Chatterjee S, Chou J, Roizman B. 1993. Replication, establishment of latency and induced reactivation of herpes simplex virus $\mu_{1} 34.5$ deletion mutants in rodent models. J Clin Invest 91:28372847.

Wyler R, Engels M, Schwyzer M. 1989. Infectious bovine rhinotracheitis/vulvovaginitis (BHV-1). In: Whittmann $\mathrm{G}$, editor. Herpesvirus Diseases of cattle, horses, and pigs. Developments in veterinary virology. Boston: Kluwer Academic Publishers. pp 1-172.

Yamauchi Y, Wada K, Goshima F, Daikoku T, Ohtsuka K, Nishiyama Y. 2002. Herpes simplex virus type 2 UL14 gene product has heat shock protein (HSP)-like functions. J Cell Sci 115:2517-2527.

Zhan Q, Lord KA, Alamo I Jr, Hollander MC, Carrier F, Ron D, Kohn KW, Hoffman B, Liebermann DA, Fornace A Jr. 1994. The gad and MyD genes define a novel set of mammalian genes encoding acidic proteins that synergistically suppress cell growth. Mol Cell Biol 14:2361-2371.

Zhu H, Shen Y, Shenk T. 1995. Human cytomegalovirus IE1 and IE2 proteins block apoptosis. J Virol 69:7960-7970. 